\title{
БЮДЖЕТНОЕ ФИНАНСИРОВАНИЕ СОЦИАЛЬНОЙ СФЕРЫ РЕСПУБЛИКИ БЕЛАРУСЬ
}

\section{(c) 2020 Самоховец Мария Павловна}

кандидат экономических наук, доцент кафедры финансов

Полесский государственный университет, Республика Беларусь, Пинск

E-mail:samkhvec@rambler.ru

(c) 2020 Бухтик Марина Игоревна

кандидат экономических наук, доцент кафедры финансов Полесский государственный университет, Республика Беларусь, Пинск

E-mail:marina_buhtik@mail.ru

\section{(c) 2020 Киевич Александр Владимирович}

доктор экономических наук, профессор кафедры финансов Полесский государственный университет, Республика Беларусь, Пинск

E-mail: a.v.kievich@yandex.ru

В статье рассматривается социальная сфера Республики Беларусь в контексте её финансирования из консолидированного бюджета; выявлены последние тенденции процесса бюджетного финансирования.

Ключевые слова: социальная сфера, финансирование, консолидированный бюджет, расходы, Республика Беларусь.

Социальная сфера в Республике Беларусь (РБ) включает в себя группу отраслей национального хозяйства, производящих услуги для жизнеобеспечения населения [1]. Социальная сфера выделяется в структуре национальной экономики по назначению производимых услуг - удовлетворение потребностей общества в трудовой деятельности, социально-экономической активности, духовной культуре.

Услуги социальной сферы в РБ создаются и предоставляются в интересах всего общества путём применения преимущественно умственного труда, а их производство и потребление возможно не только за счёт бюджетных расходов, но и с применением рыночных методов.

Отметим, что все расходы бюджета, имея универсальный характер, в конечном итоге имеют целью повышение качества жизни населения и традиционно финансируются из государственного бюджета [2]. В соответствии с действующей бюджетной классификацией Республики Беларусь [3] к социальной сфере можно отнести следующие разделы:

- 07 «Здравоохранение»

- 08 «Физическая культура, спорт, культура и средства массовой информации»

- 09 «Образование»

- 10 «Сциальная политика»

В таблице 1 представлены данные в динамике за 2010-2019 гг. о доле расходов на социальную сферу в расходах консолидированного бюджета Республики Беларусь.

Таблица 1. Доля бюджетных расходов на социальную сферу в консолидированном бюджете РБ (январь-декабрь)

\begin{tabular}{|l|c|c|c|c|c|c|c|c|c|c|}
\hline Направление расходов & $\mathbf{2 0 1 0}$ & $\mathbf{2 0 1 1}$ & $\mathbf{2 0 1 2}$ & $\mathbf{2 0 1 3}$ & $\mathbf{2 0 1 4}$ & $\mathbf{2 0 1 5}$ & $\mathbf{2 0 1 6}$ & $\mathbf{2 0 1 7}$ & $\mathbf{2 0 1 8}$ & $\mathbf{2 0 1 9}$ \\
\hline Здравоохранение & 12,2 & 13,1 & 13,1 & 13,5 & 14,1 & 14,0 & 14,5 & 15,0 & 12,3 & 13,3 \\
\hline $\begin{array}{l}\text { Физическая культура, спорт, } \\
\text { культура и средства массо- } \\
\text { вой информации }\end{array}$ & 3,3 & 3,3 & 3,3 & 3,2 & 3,2 & 3,1 & 3,2 & 3,3 & 2,9 & 3,2 \\
\hline Образование & 15,7 & 17,3 & 16,7 & 17,2 & 17,4 & 16,7 & 16,8 & 17,1 & 14,4 & 15,6 \\
\hline Социальная политика & 9,4 & 9,6 & 8,4 & 8,0 & 8,1 & 8,7 & 8,9 & 8,5 & 7,0 & 7,1 \\
\hline $\begin{array}{l}\text { Расходы консолидирован- } \\
\text { ного бюджета, всего }\end{array}$ & $\mathbf{4 0 , 6}$ & $\mathbf{4 3 , 2}$ & $\mathbf{4 1 , 6}$ & $\mathbf{4 1 , 9}$ & $\mathbf{4 2 , 9}$ & $\mathbf{4 2 , 5}$ & $\mathbf{4 3 , 3}$ & $\mathbf{4 3 , 9}$ & $\mathbf{3 6 , 5}$ & $\mathbf{3 9 , 1}$ \\
\hline
\end{tabular}

Источник: собственная разработка на основе данных официальной статистики 
Как видно из таблицы 1 , доля расходов на социальную сферу в расходах консолидированного бюджета РБ составляет от $36,5 \%$ до 39,1\% за исследуемый период 2010-2019 гг. В целом показатели по отдельным направлениям социальной сферы характеризуются стабильностью, за исключением социальной политики (уменьшение в 2019 г. на 2,3 п.п. по сравнению с 2010 г.).

Выделим следующие основные направления бюджетных расходов на социальную сферу в РБ.

В области здравоохранения финансируются расходы на руководство и содержание организаций здравоохранения (медицинские услуги, закупки лекарственных средств, изделий медицинского назначения и оборудования, оказание санаторно-курортных услуг); осуществление санитарного надзора; прикладные научные исследования в области здравоохранения и др.

По направлению физической культуры, спорта, культуры и средств массовой информации финансируется руководство и осуществление деятельности в области культуры и искусства; поддержка национального киновидеопроизводства и киновидеопроката, издательств и периодических СМИ; вопросы религии; прикладные научные исследования в области физической культуры, спорта, культуры и СМИ.

В области образования финансируются расходы по управлению и обеспечению функционирования учреждений образования, послевузовское образование; дополнительное образование взрослых; прикладные исследования в области образования; проведение централизованных мероприятий; подготовке, выпуску, комплектованию и доставке учебных пособий; поддержка обучающихся, достигших высоких показателей в учебной и общественной работе.

Финансирование социальной политики предполагает расходы по обеспечению функци- онирования учреждений социального обслуживания, выплаты государственных социальных пособий и пенсий (например, военнослужащим, работникам правоохранительных органов); государственные программы, касающиеся детей, молодежи, женщин, семьи; содействию занятости; поддержке строительства (реконструкции) жилья для отдельных категорий граждан; социальной помощи лицам, проживающим в зонах экологического бедствия и др.

Динамика расходов консолидированного бюджета по всем направлениям социальной сферы представлена в таблице 2.

Данные таблицы 2 свидетельствуют о том, наибольший объём бюджетного финансирования социальной сферы за период 2016-2019 гг. наблюдается в 2017 году, а наименьший - в 2018 году. Вместе с тем, на более продолжительном временном отрезке с 2010 по 2019 годы расходы бюджета имели положительную динамику с 2010 по 2018 год. Заметно значительное сокращение бюджетных расходов на социальную сферу в 2018 году (рисунок 1), после чего в 2019 году они снова увеличились.

Доли финансирования каждого из направлений в расходах на социальную сферу располагаются в следующей очередности (по убыванию): образование; здравоохранение; социальная политика; физическая культура, спорт, культура и СМИ (рисунок 2).

В мировой практике, в том числе в целях международной сопоставимости показателей, широко используется классификация функций органов государственного управления (КФОГУ) [4].

Проведём сравнение принятых классификаций государственных расходов на социальную сферу в Беларуси и зарубежных странах (таблица 3).

Можно сделать вывод, что в целом бюджет-

Таблица 2. Бюджетные расходы на социальную сферу из консолидированного бюджета РБ (январь-декабрь)

\begin{tabular}{|l|c|c|c|c|c|c|c|c|}
\hline \multirow{2}{*}{ Направление расходов } & \multicolumn{2}{|c|}{2016} & \multicolumn{2}{c|}{2017} & \multicolumn{2}{c|}{2018} & \multicolumn{2}{c|}{2019} \\
\cline { 2 - 9 } & руб. & $\%$ & руб. & \% & руб. & \% & руб. & \% \\
\hline Здравоохранение & 3953,9 & 33,4 & 4305,1 & 34,2 & 3366,7 & 33,7 & 3813,8 & 33,9 \\
\hline $\begin{array}{l}\text { Физическая культура, спорт, } \\
\text { культура и средства массовой } \\
\text { информации }\end{array}$ & 864,2 & 7,3 & 937,2 & 7,4 & 793,9 & 8,0 & 905,8 & 8,1 \\
\hline Образование & 4593,7 & 38,8 & 4914,8 & 39,0 & 3921,3 & 39,3 & 4471,9 & 39,8 \\
\hline Социальная политика & 2428,7 & 20,5 & 2447,9 & 19,4 & 1900,5 & 19,0 & 2049,6 & 18,2 \\
\hline $\begin{array}{l}\text { Расходы на социальную } \\
\text { сферу, всего }\end{array}$ & $\mathbf{1 1 8 4 0 , 5}$ & $\mathbf{1 0 0 , 0}$ & $\mathbf{1 2 6 0 5 , 0}$ & $\mathbf{1 0 0 , 0}$ & $\mathbf{9 9 8 2 , 4}$ & $\mathbf{1 0 0 , 0}$ & $\mathbf{1 1 2 4 1 , 1}$ & $\mathbf{1 0 0 , 0}$ \\
\hline
\end{tabular}

Источник: собственная разработка на основе данных официальной статистики 


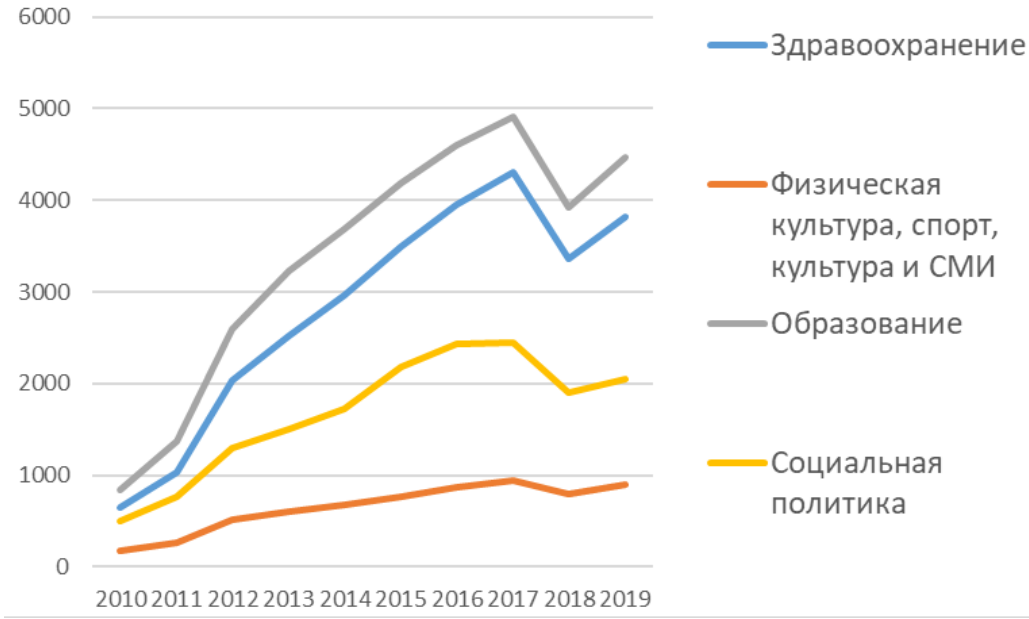

Рисунок 1. Динамика расходов консолидированного бюджета

Республики Беларусь на социальную сферу за 2010-2019 годы Источник: собственная разработка на основе данных официальной статистики

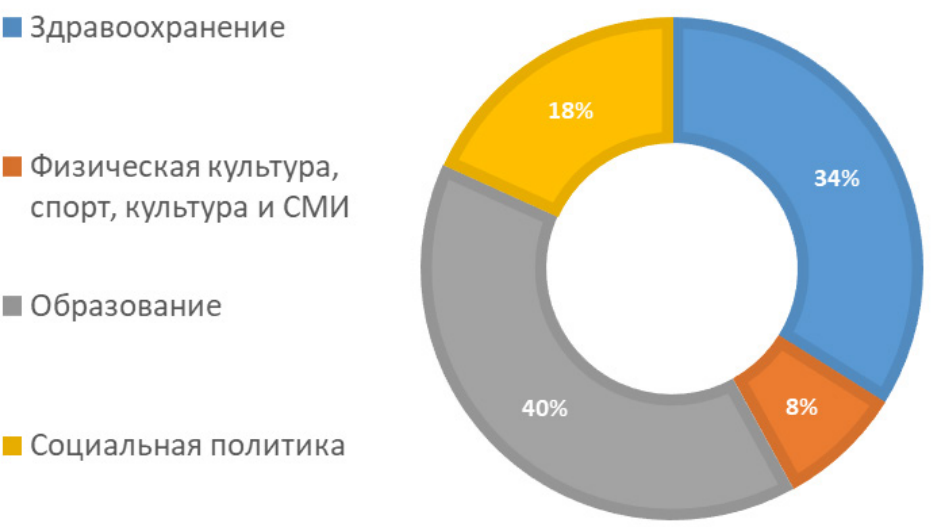

Рисунок 2. Структура расходов консолидированного бюджета Республики Беларусь на социальную сферу в 2019 году Источник: собственная разработка на основе данных официальной статистики
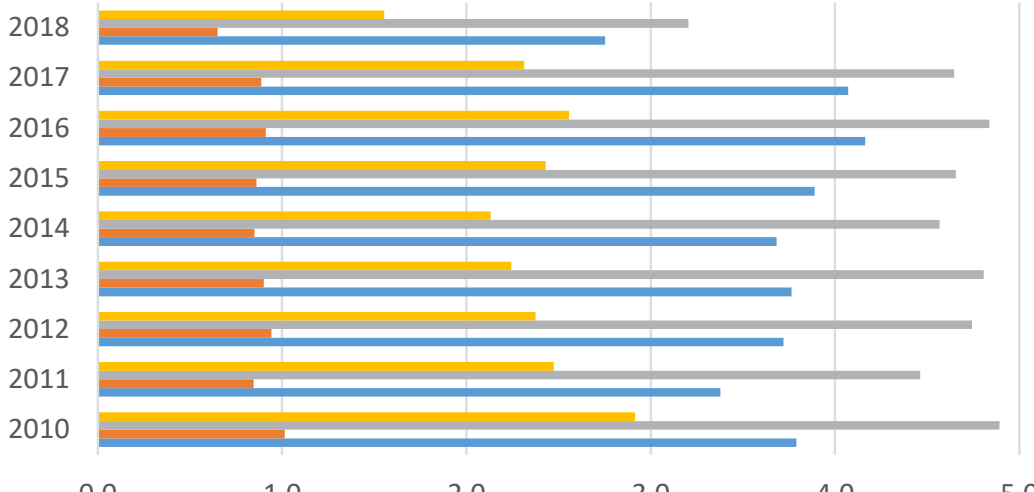
0,0
1,0
2,0
3,0
4,0
5,0
6,0

Социальная политика

Образование

Физическая культура, спорт, культура и СМИ ш Здравоохранение

Рисунок 3. Бюджетные расходы на социальную сферу по отношению к ВВП (\%) Источник: собственная разработка на основе данных официальной статистики 
Таблица 3. Классификация государственных расходов на социальную сферу

\begin{tabular}{|c|c|}
\hline $\begin{array}{c}\text { Бюджетная классификация РБ } \\
\text { (Минфин РБ, 2008) }\end{array}$ & $\begin{array}{c}\text { Руководство по статистике государственных } \\
\text { финансов (МВФ, 2014) }\end{array}$ \\
\hline \multicolumn{2}{|c|}{ ЗДРАВООХРАНЕНИЕ } \\
\hline $\begin{array}{l}\text { Медицинская помощь населению } \\
\text { Государственный санитарный надзор } \\
\text { Прикладные исследования в области здравоохране- } \\
\text { ния } \\
\text { Другие вопросы в области здравоохранения }\end{array}$ & $\begin{array}{l}\text { Медицинские изделия, оборудование и аппараты } \\
\text { Амбулаторные услуги } \\
\text { Услуги больниц } \\
\text { Услуги в области здравоохранения } \\
\text { НИОКР в области здравоохранения } \\
\text { Вопросы здравоохранения, не отнесенные к другим } \\
\text { категориям }\end{array}$ \\
\hline ФИЗИЧЕСКАЯ КУЛЬТУРА, СПОРТ, КУЛЬТУРА И СМИ & ОТДЫХ, КУЛЬТУРА И РЕЛИГИЯ \\
\hline $\begin{array}{l}\text { Физическая культура и спорт } \\
\text { Культура } \\
\text { Средства массовой информации } \\
\text { Прикладные исследования в области физической } \\
\text { культуры, спорта, культуры и средств массовой ин- } \\
\text { формации } \\
\text { Вопросы религии и другие вопросы в области физи- } \\
\text { ческой культуры, спорта, культуры и средств массо- } \\
\text { вой информации }\end{array}$ & $\begin{array}{l}\text { Услуги по организации отдыха и занятий спортом } \\
\text { Услуги в области культуры } \\
\text { Услуги, связанные с радио- и телевизионным веща- } \\
\text { нием и издательским делом } \\
\text { Услуги, связанные с религией, и другие обществен- } \\
\text { ные услуги } \\
\text { НИОКР в области отдыха, культуры и религии } \\
\text { Вопросы отдыха, культуры и религии, не отнесенные } \\
\text { к другим категориям }\end{array}$ \\
\hline \multicolumn{2}{|c|}{ ОБРАЗОВАНИЕ } \\
\hline $\begin{array}{l}\text { Дошкольное образование } \\
\text { Общее среднее образование } \\
\text { Профессионально-техническое образование } \\
\text { Среднее специальное образование } \\
\text { Высшее и послевузовское образование } \\
\text { Дополнительное образование взрослых } \\
\text { Дополнительное образование детей и молодежи } \\
\text { Прикладные исследования в области образования } \\
\text { Другие вопросы в области образования }\end{array}$ & $\begin{array}{l}\text { Дошкольное и начальное образование } \\
\text { Среднее образование } \\
\text { Продолженное среднее образование } \\
\text { Высшее образование } \\
\text { Образование, не подразделенное по ступеням } \\
\text { Вспомогательные услуги в системе образования } \\
\text { НИОКР в области образования } \\
\text { Вопросы образования, не отнесенные к другим кате- } \\
\text { гориям }\end{array}$ \\
\hline СОЦИАЛЬНАЯ ПОЛИТИКА & СОЦИАЛЬНАЯ ЗАЩИТА \\
\hline $\begin{array}{l}\text { Социальная защита } \\
\text { Пенсионное обеспечение } \\
\text { Помощь семьям, воспитывающим детей } \\
\text { Государственная молодежная политика } \\
\text { Содействие занятости населения } \\
\text { Помощь в обеспечении жильем } \\
\text { Прикладные исследования в области социальной } \\
\text { политики } \\
\text { Другие вопросы в области социальной политики } \\
\text { (в т.ч. ФСЗН) }\end{array}$ & $\begin{array}{l}\text { Заболевания и нетрудоспособность } \\
\text { Старость } \\
\text { Иждивенцы, оставшиеся без кормильца } \\
\text { Семья и дети } \\
\text { Безработица } \\
\text { Жилье } \\
\text { Вопросы социальной неустроенности, не отнесенные } \\
\text { к другим категориям } \\
\text { НИОКР в области социальной защиты } \\
\text { Вопросы социальной защиты, не отнесенные к дру- } \\
\text { гим категориям }\end{array}$ \\
\hline
\end{tabular}

Источник: собственная разработка на основе данных официальной статистики

ная классификация в РБ соответствует принятой в мировой практике, хотя и не полностью совпадает с ней [5]. Кроме того, проводя анализ структуры расходов на социальную сферу необходимо учитывать, что государственные социальные фонды также можно отнести к расходам на социальную сферу (в мировой практике формируются различные фонды по ведомственной подчиненности и целям). Однако с 2010 г. в РБ Фонд социальной защиты населения Министерства труда и социальной защиты Республики Беларусь (ФСЗН) является государственным внебюджетным фондом и его расходы выведены из состава республиканского бюджета.

Бюджетные расходы в Беларуси на социальную сферу по отношению к ВВП с 2010 по 2018 годы представлены на рисунке 3.

Бюджетные расходы на социальную сферу в РБ складываются на уровне до 5\% ВВП, что меньше аналогичных расходов европейских стран (например, в числе стран-лидеров по объемам бюджетного финансирования образования и здравоохранения - Норвегия, Швеция - рис. 4 и 5).

Таким образом, на основе проведенного анализа и оценки бюджетного финансирования 


10,0 - Беларусь — Киргизстан — Норвегия — Франция — Швеция — Россия

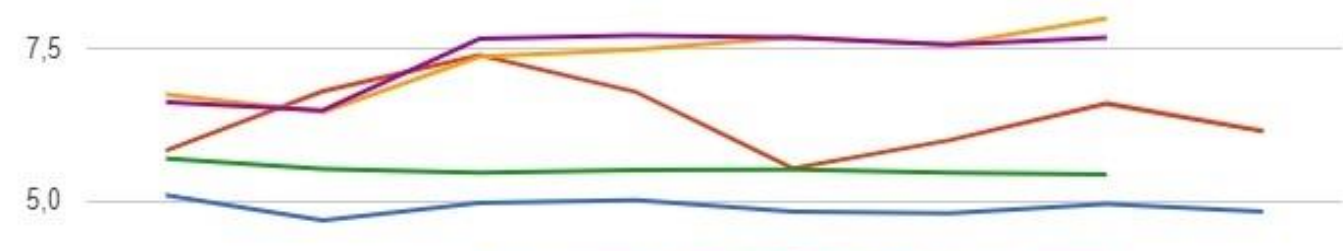

2,5

0,0

$\begin{array}{llllllll}2010 & 2011 & 2012 & 2013 & 2014 & 2015 & 2016 & 2017\end{array}$

Рисунок 4. Бюджетные расходы на образование в некоторых странах Источник: на основе данных Всемирного банка [6]

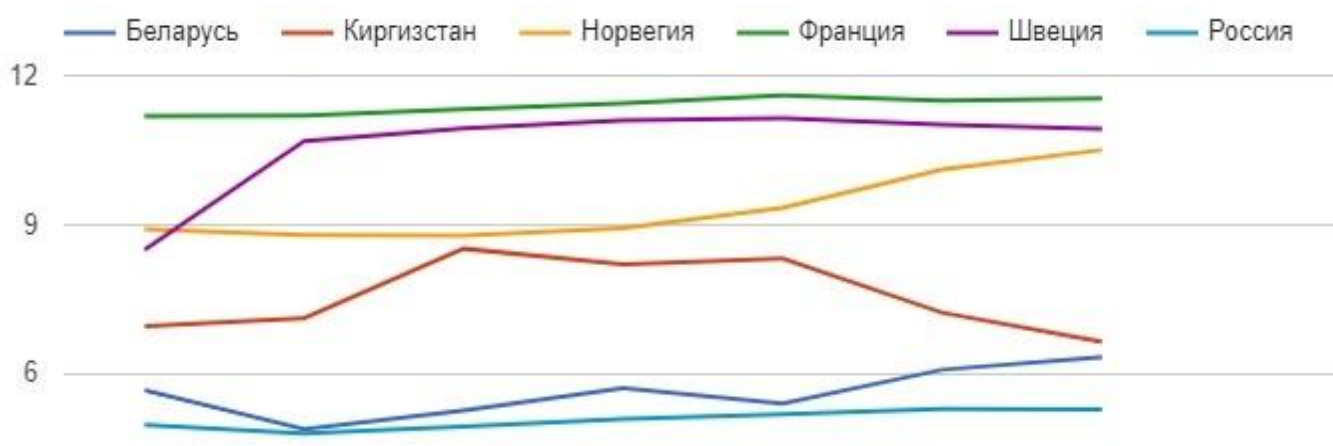

3

0

$\begin{array}{llllllll}2010 & 2011 & 2012 & 2013 & 2014 & 2015 & 2016 & 2017\end{array}$

Рисунок 5. Бюджетные расходы на здравоохранение в некоторых странах Источник: на основе данных Всемирного банка [6]

социальной сферы Республике Беларусь можно сделать следующие выводы:

1. Динамика расходов на социальную сферу в целом положительная, на финансирование социальной сферы в 2019 году приходилось $39,1 \%$ от расходов консолидированного бюджета.

2. Классификация государственных расходов на социальную сферу в Республике Беларусь близка к международной классификации.

3. Наибольший удельный вес в расходах на социальную сферу занимает образование и здравоохранение - 40\% и 34\% соответственно.

4. Уровень расходов на социальную сферу составляет до 5\% ВВП и имеет резервы увеличения.

В заключение отметим, что бюджетное финансирование социальной сферы Республики Беларусь имеет особое значение в рамках реализации модели социально-ориентированной рыночной экономики и в будущем вполне может совершенствоваться [7]. 


\section{Библиографический список}

1. Будкевич, К.А. Финансирование социальной сферы Республики Беларусь: проблемы и пути решения / K.А. Будкевич, М.П. Самоховец // SCI-ARTICLE.RU: научный периодический рецензируемый электронный журнал. - 2018. - № 54.- С. 219-225.- С. 219.

2. Самоховеи, М.П. Роль финансового рынка в инвестиционной политике / М.П. Самоховец // Белорусский экономический журнал: ежеквартальный научно-практический журнал. - 2016. - № 2.- С. 45-56.- С. 5051.

3. Постановление Министерства финансов Республики Беларусь от 31.12.2008 № 208 «О бюджетной классификации Республики Беларусь». Система КонсультантПлюс.

4. Government finance statistics manual 2014.- Washington, D.C.: International Monetary Fund, 2014 URL: https:// www.imf.org/external/Pubs/FT/GFS/Manual/2014/gfsfinal.pdf.

5. Киевич А.В. Финансовые аспекты функционирования фонда социальной защиты населения в Республике Беларусь / А. В. Киевич // Вопросы экономики и права. - 2017._- № 7 (109). - С. 23-27.

6. [Электронный ресурс] - Доступно на: http://documents.vsemirnyjbank.org/curated/ru /550301468014421797/ pdf/741480ESWOP123032700PUBLIC00Russian.pdf. - Дата доступа: 30.02.2020 г.

7. Киевич А.В., Койпаш Д.А. Краудинвестинг как альтернативная модель финансирования инвестиционного проекта / А. В. Киевич, Д.А. Койпаш // Экономика и банки. 2016. № 1. С. 58-65. 